\title{
The Burden of Injury in terms of Economic Loss and Disability Days: A Community Based Study from Eastern Nepal

\author{
Ghimire A, ${ }^{1}$ Nagesh $S,{ }^{2}$ Jha $N,{ }^{1}$ Niraula SR, ${ }^{1}$ Devkota $S^{3}$ \\ ${ }^{1}$ School of Public Health and Community Medicine \\ ABSTRACT \\ BPKIHS, \\ Background
}

Dharan, Nepal.

${ }^{2}$ Department of Community Medicine

Lady Harding Medical College

New Delhi, India.

${ }^{3}$ Research Fellow

KAla-drug R Project, BPKIHS

Dharan, Nepal

Injuries are already a substantial public Health problem all over the world and are expected to increase in the 211st Century. They are major causes of deaths and disability in the population and also involve high societal costs.

\section{Objectives}

This study was designed to assess the economic loss due to the injury and the disability days due to different types of injuries.

\section{Methods}

A systematic random sampling technique was used to select 1388 households from 19 wards. A detailed questionnaire was used to collect information related to injuries to the persons suffered from injuries including treatment obtained, cost of treatment (direct/indirect cost) and length of disability.

Corresponding author

Dr. Anup Ghimire

Results

Among the minor injured persons, majority (93.2\%) did not spend any indirect cost. $36.7 \%$ of the major inured persons spent Nepalese rupees 10,001 to NRs 100,000 as direct treatment costs. But $50 \%$ spent less than 5000 NRs as indirect cost for major injury treatment. Maximum number $(67.4 \%)$ of major injured persons had disability days of 31 to 90 days.

BPKIS, Dharan, Nepal

Email: ghimire.anup@gmail.com

\section{Conclusion}

The high incidence of injuries, especially road traffic injuries, adds a huge economic burden to nation.

\section{Citation}

Ghimire A, Nagesh S, Jha N, Niraula SR, Devkota $S$. The burden of injury in terms of economic loss and disability days: a community based study from eastern Nepal. Kathmandu Univ Med J 2011;34(2)27-30.

\section{KEY WORDS \\ injury, disability days, economic burden}

\section{INTRODUCTION}

Injury has become a leading cause of death and disability worldwide. It is estimated that 5.8 million people die annually from road traffic crashes, burns, falls, unintentional injury, violence, and suicide. Injury accounts for $10 \%$ of the world's deaths. Millions more are disabled, temporarily or permanently, from injury. In addition to deaths and disabilities, there is a very significant economic loss from injury, both from treatment costs as well as lost wages and economic productivity. These costs are especially severe as many of those injured are working aged adults. In Lowand middle-income countries (LMICs), the economic cost of road traffic injuries alone has been estimated at nearly US\$100 billion, which is twice the sum of all development assistance. Most countries lose one to two percent of their GDP in injury related consequences from road traffic crashes. In addition to these macroeconomic costs, there is an enormous toll of economic hardships on the part of injured persons and their families. This is especially severe in LMICs. A severe illness or injury is often the event that sinks a family living on the margin into deeper poverty. ${ }^{1}$

Injuries are already a substantial public Health problem all over the world and are expected to increase in the 211st Century. They are major causes of deaths and disability in the population and also involve high societal costs. ${ }^{2}$ The toll of human suffering from injury is usually measured by 
mortality and disability rates, economic costs of treatment and lost of productivity but limited attention has been directed towards the economic costs of injury in low income countries like Nepal. ${ }^{3} \mathrm{Nepal}$ is one of the poorest countries in the world, with a per capita GDP of US $\$ 200$ and life expectancy at birth of 54 years in 1994(World Bank 1996). On average, health care accounts for about $5.5 \%$ of total household expenditure. The share of total expenditure devoted to health care increases with the level of household income. In terms of the role of households in the total health economy, out of pocket contributions account for almost three-quarters of the total funds used to finance Nepals health care sector. ${ }^{4}$

Due to political instability of the country, the government has been failure to provide social and economic justice and welfare to millions of people living under condition of deprivation. Failure to do work in this direction within a reasonable time frame may generate social burden and chaos.

In this study, minor injury is considered as an injury that results in disability less than 30 days and major injury is as an injury that results in a disability lasting more than 30 days. ${ }^{5}$ This study is designed to assess the economic loss due to the injury and the disability days due to the different types of injuries.

\section{METHODS}

Dharan is a town situated at the foot of the mighty Himalayas in the Eastern region of Nepal. The population of Dharan Municipality is 95332 with 13853 household. It has mixed ethnicity comprising of Rai, Newar, Limbu, Brahmin, Chhetri, Tamang, Magar, Gurung and others. ${ }^{6}$

This community based cross-sectional study was conducted during 2004 to 2005 . Where $10 \%$ of the households of Dharan i.e. 1388 households were taken as a sample size. To select the required sample size from 19 wards, systematic random sampling technique was used. Detailed questionnaires were used among injured persons to collect information on treatment obtained, cost of treatment (direct/indirect cost) and length of disability.

The injured persons were asked about the place they went for treatment of their injury. They were also asked about the treatment costs which included direct total cost was calculated from doctor's fee, medicine, any undergone operations, hospital charges and investigation charges. Indirect total cost was calculated from transportation cost, loss of daily wages of the person, lodging and fooding of the attendants, etc.

The collected data was entered in Microsoft Excel. SPSS version 11.5 was used for analysis and percentage, proportions and prevalence rates were calculated. Chisquare test was applied to examine significance of the variables. $P$ value was set at $5 \%$ level of significance.

\section{RESULTS}

Of the total surveyed population (7063), prevalence of minor injuries were $3.5 \%$ during the preceding recall of one month and major injuries were $0.7 \%$ during preceding recall of one year.

Among minor injured persons, most common treatment place $(52.4 \%)$ was home, followed by medical shop $22.0 \%$ and hospital $13.6 \%$. Common treatment place for major injuries were hospital (87.8\%), followed by local medical practitioner (12.2\%).
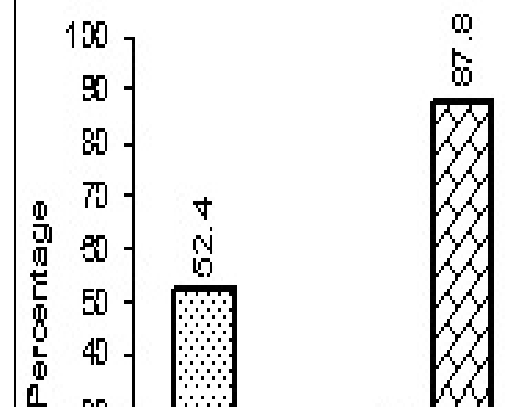

Fig.1. Distribution of injuries according to the place of management.

In terms of direct treatment costs, most of the minor, injured victims (69.6\%) spent below 100 Nepalese rupees. Likewise, 24.8\% victims spent from 101 to 1000 NRs for treatment and only 6.4\% spent more than 1001 to 10000 NRs for their treatment (Table 1). On the basis of three categories, <100 NRs., (101 to 1,000) NRs. and (1001 to $10,000)$ NRs., the direct and indirect costs are significantly associate with the minor injures (chi square $=63.63$, $\mathrm{p}<0.001)$.

Table 1. Direct / Indirect treatment costs among the persons with minor injuries.

\begin{tabular}{|lll|}
\hline Rupees (NRs.) & Direct cost No. (\%) & Indirect cost No. (\%) \\
\hline None & $0(0)$ & $233(93.2)$ \\
\hline$<100$ & $174(69.6)$ & $8(3.2)$ \\
\hline $101-1000$ & $60(24.0)$ & $7(2.8)$ \\
\hline $1001-10000$ & $16(6.4)$ & $2(0.8)$ \\
\hline Total & $250(100.0)$ & $250(100.0)$ \\
\hline
\end{tabular}

Table 2. Direct / Indirect treatment costs among the persons with major injuries.

\begin{tabular}{|lll|}
\hline Rupees (NRs.) & Direct cost No. (\%) & Indirect cost No. (\%) \\
\hline None & $17(34.7)$ & $19(50.0)$ \\
\hline$<100$ & $7(14.3)$ & $5(13.2)$ \\
\hline $101-1000$ & $18(36.7)$ & $13(34.2)$ \\
\hline $1001-10000$ & $7(14.3)$ & $1(2.6)$ \\
\hline Total & $49(100.0)$ & $38(100.0)$ \\
\hline
\end{tabular}


Among the minor injured persons, majority (93.2\%) did not spend any indirect cost. But 3.2\% spent less than NRs 100 as indirect treatment cost. Similarly, $2.8 \%$ and $0.8 \%$ victims spent indirect cost of NRs 101 to 1000 and more than NRs 1001 to 10000 for their treatment respectively.

Table 2 shows that $36.7 \%$ of the major inured persons spent $(10,001$ to 100,000$)$ NRs as direct treatment costs for treatment. In case of indirect cost, $50 \%$ spent less than 5,000 NRs as for major injury treatment. Very less numbers (2.6\%) of persons spent more than 100,000 as indirect cost for treatment. But, the direct cost and indirect cost are not statistically associated with the costs involved in major injuries.

Table 3. Days lost due to disability among the persons with minor injuries.

\begin{tabular}{|ll|}
\hline Days & No. (\%) \\
\hline None & $221(88.4)$ \\
\hline $1-7$ & $22(8.8)$ \\
\hline $8-14$ & $6(2.4)$ \\
\hline 15 & $1(0.4)$ \\
\hline Total & $250(100.0)$ \\
\hline
\end{tabular}

Table 4. Days lost due to disability among the persons with major injuries.

\begin{tabular}{|ll|}
\hline Days & No. $(\%)$ \\
\hline $31-90$ & $33(67.4)$ \\
\hline $91-180$ & $10(20.4)$ \\
\hline $181-270$ & $5(10.2)$ \\
\hline 271 & $1(2.0)$ \\
\hline Total & $49(100.0)$ \\
\hline
\end{tabular}

\section{Disability days due to injuries}

The injured persons were also asked about how many days they could not perform normal work (going toilet, taking bath, eating etc), could not go to school, working place and any restriction to social activities.

The disability days among minor injured people were very less. Most of them (88.4\%) did not have a disability day (Table 3).

Maximum number (67.4\%) of major injured persons had disability days of 31 to 90 days. Likewise, $20.4 \%$ of injured had 91 to 180 days of disability and $10.2 \%$ had 181 to 270 days of disability. Only $(2.0 \%)$ had the disability days to more than 271 days (Table 4).

\section{DISCUSSION}

In this study, more than half (52.4\%) persons had treatment at home and $22.0 \%$ at medical shop among minor injured. Similar finding was observed by Tiagi $\mathrm{C}$ et al. in India, where home treatment was more common, followed by doctor consultation. ${ }^{8}$ Shaikh MA et al in Pakistan also obtained the similar results. ${ }^{9}$ Common treatment place for major injuries was hospital (87.8\%) and medical practitioner $(12.2 \%)$. None of the major injured went to the medical shop and traditional healers for their treatment. But surprisingly, $5.6 \%$ of the minor injured persons still went to the traditional healers for injury treatment.

In terms of direct treatment costs (including doctor fee, medicine, any operation, hospital charge and investigation etc), most of the minor injured person (69.6\%) spent below 100 NRs. Similarly $24.0 \%$ of the victims spent from NRs. 101 to 1000 for treatment and $6.4 \%$ spent more than NRs. 1001 to 10000 for their treatment. Whereas $93.2 \%$ did not spent any indirect treatment cost. Only $3.2 \%$ spent less than 100 Nepalese rupees as indirect treatment cost. Likewise, $2.8 \%$ and $0.8 \%$ victims spent indirect cost of NRs. 101 to 1000 and more than NRs. 1001 to 10000 for their treatment respectively. Study done by Rajbhandari SD et al. in rural area of eastern Nepal found that $84.0 \%$ minor injured persons spend below NRs. 100 as direct treatment cost whereas $87.0 \%$ of the participants did not spend any indirect treatment cost for minor injuries. ${ }^{10}$ The estimated median cost (direct and indirect) per minor injury was NRs 150 and range from NRs 2 to NRs 10,500. On the basis of three categories, <100 NRs. (101 to 1,000) NRs. and (1001 to 10,000) NRs., the direct and indirect costs are significantly associate with the minor injures (Chi-square $=$ 63.63, $\mathrm{p}<0.001)$.

This study shows that $36.7 \%$ of the major injured person spent Nepalese rupees 10,001 to 100,000 as direct treatment cost. Similarly $34.7 \%$ spent less than NRs. 5,000 and equal percentage of injured persons (14.3\%) spent from 5,000 to 10,000 and more than 100,000 NRs as direct cost for their treatment, where as half of the injured person (50.0\%) spent less than 5,000 NRs as indirect cost (including transportation cost, attendants loss, lodging and fooding etc), followed by $34.2 \%$ and $13.2 \%$ persons spent from 10,001 to $100,000 \mathrm{NRs}$ and 5,000 to10,000 NRs as indirect cost respectively. Median cost was NRs 15500 per major injury and range from NRs 500 to 220,500 . Study done by Salifu IM et al in Ghana found that median cost was US\$ 25 (NRs 1800) and range from US \$3 (NRs 216 ) to US\$1,600 (NRs 115,200) in which minor and major injury treatment cost were combined together. ${ }^{11}$ These differences between expenditure costs may be because of the two different nations have different cost of medical services. (Chi square $=2.19, \mathrm{p}=0.33$ )

This study shows that disability days among minor injured people were very less. Most of them (88.4\%) did not have a disability day. Among disability day due to minor injury $8.8 \%$ lost 1 to 7 days and $2.4 \%$ people lost 8 to 14 days. Similarly only $0.4 \%$ people lost more than 15 days due to minor injury. This is expected because most of the persons 
with minor injuries are able to carry on their normal work even after the injury. This is supported by a study of Verma PK in Haryana in which he found $26.5 \%$ of the minor injury disabled the victim for 4 to 7 days. ${ }^{12}$

Our study also showed that maximum number (67.4\%) of major injured persons had disability days of 31 to 90 days. Likewise, $20.4 \%$ of injured had 91 to 180 days of disability and $10.2 \%$ had 181 to 270 days of disability. Only $2.0 \%$ had the disability days of more than 271 days. This was because fractures / dislocations were common cause of major injuries, which makes a persons disabled for 1 to 3 months or more. Study done by Salifu IM in Kumasi, Ghana found that average disability days for major injuries were $50.7 \%$ days due to pedestrian injuries and among 29 injury victims, 8 persons had been disabled for more than three months at the time of the interview and could still not return to normal life. ${ }^{11}$
The present study may have the probability of underreporting events such as suicides and assaults, the total costs for the some injured persons could not be estimated accurately as they were under treatment during interview and also, disability due to older injuries occurring in previous years causing permanent impairment was not evaluated, thus, they were under limitation of this study.

\section{CONCLUSION}

Injury has become a leading cause of death and disability worldwide. In addition to deaths and disabilities, there is a very significant economic loss from injury, both from treatment costs as well as lost wages and economic productivity. There is an enormous toll of economic hardships on the part of injured persons and their families.

\section{REFERENCES}

1. The challenge of lowering the burden of injury globally and in the WHO Eastern Mediterranean Region, Discussion Paper 5 May 2009 WHO. http://www.un.org/ecosoc/newfunct/pdf/ Discussion\%20 Paper\%20on\%20Injuries\%20-\%205\%20May\%202009.pdf

2. Laur A. Health economy information in developing countries. Injury prevention and control. 5th world conference. Published by Rajiv Beri for Macmillan India Limited, New Delhi; 2000.p. 605.

3. Mock CN, Gloyd S, Gish O, Adjei S, Acheampong F. Economic cost of injury and resulting family coping strategies in Ghana. Injury prevention and control. 5th world conference. Published by Rajiv Beri for Macmillan India Limited, New Delhi 2000; p.167.

4. Hotchkiss RD, Rous JJ, Karmacharya K, Sangraula P. Household health expenditures in Nepal: implications for health care financing reform. Health policy and planning; 13(4):371-83.

5. Mock CN, Abatanga F, Cummingi $P$ and Koepsell TD. "Incidence and outcome of injury in Ghana: A community based survey. WHO Health Bulletin 1999: 77:12.

6. B.P. Koirala Institute of Health Sciences. Prospectus of Postgraduate Programme. Dharan: BPKIHS; 2003.

7. Ghimire A, Nagesh S, Jha N, Niraula SR, Devkota S. An epidemiological study of injury among urban population.Kathmandu Univ Med J 2009; 7 (4): 402-7.

8. Tiagi $C$, Walia L, Singh A. Prevalence of Minor Injuries Among under fives in a Dhandigarh Slum. India pediatrics 2000; 37: 755-8.

9. Shaikh MA, Kamal A. Three month prevalence and profile of injury in University students - perspective from Pakistan. Pakistan Journal of Medical Science 2001; 17(4): 215 - 9.

10. Rajbhandari SD, Jha N, Niraula SR, Nagesh S. Prevalence of different types of injury in a rural community of Eastern Nepal. Unpublished Thesis work, BPKIHS 2002.

11. Salifu IM, Mock C. Pedestrian injuries in Kumasi results of an epidemiologic survey. The Ghana engineer 1998; 23-7.

12. Verma PK. An epidemiological study of accidents among rural population. Health Department, MCD; Delhi. In: Abstract. Injury prevention and control. 5th world conference. Published by Rajiv Beri for Macmillan India Limited, New Delhi; 2000.p. 255. 